\title{
Pilot Study: Magnesium Sulphate Administration and Early Resolution of Hypoxic Ischemic Encephalopathy in Severe Perinatal Asphyxia
}

\author{
Simon Pius ${ }^{*}$, Mustapha Belloㅁ, Jose Pwavimbo Ambe1, Yenti Machoko', Adama Yusuf Clement², \\ Rhoda Genesis ${ }^{3}$, Mark Inusa Kamas ${ }^{4}$

\begin{abstract}
${ }^{1}$ Department of Paediatrics, College of Medical Sciences, University of Maiduguri, Maiduguri, Nigeria
${ }^{2}$ Department of Economics, Faculty of Management Sciences, University of Maiduguri, Maiduguri, Nigeria

${ }^{3}$ Department of Chemical Pathology Laboratory, University of Maiduguri Teaching Hospital, Maiduguri, Nigeria

${ }^{4}$ APIN/FHI, HIV/AIDS Data Section, University of Maiduguri Teaching Hospital, Maiduguri, Nigeria
\end{abstract} \\ Email: ^simonpius2000@yahoo.co.uk, simonp@unimaid.edu.ng
}

How to cite this paper: Pius, S., Bello, M., Ambe, J.P., Machoko, Y., Clement, A.Y., Genesis, R. and Kamas, M.I. (2019) Pilot Study: Magnesium Sulphate Administration and Early Resolution of Hypoxic Ischemic Encephalopathy in Severe Perinatal Asphyxia. Open Journal of Pediatrics, 9, 89-102.

https://doi.org/10.4236/ojped.2019.91009

Received: February 21, 2019

Accepted: March 19, 2019

Published: March 22, 2019

Copyright $\odot 2019$ by author(s) and Scientific Research Publishing Inc. This work is licensed under the Creative Commons Attribution International License (CC BY 4.0).

http://creativecommons.org/licenses/by/4.0/

\section{(c) (i) Open Access}

\begin{abstract}
Introduction: Perinatal asphyxia is one of the leading causes of perinatal death and a recognized cause of neuromotor disability among survivors. About $20 \%-30 \%$ of asphyxiated newborns who develop hypoxic ischemic encephalopathy (HIE) die during the neonatal period, and one third to one half of survivors are left with cerebral palsy and mental retardation. Objective of the Study: Was to determine the effect of magnesium sulphate as neuroprotective drug in hypoxic ischemic encephalopathy resulting from severe perinatal asphyxia. Materials and Methods: A prospective administration of magnesium sulphate to 52 severely asphyxiated newborns with hypoxic ischemic encephalopathy was conducted over one year period from $1^{\text {st }}$ August 2017 to $31^{\text {st }}$ July 2018. Results: Most (96.2\%) of patients were term baby ( $\mathrm{GA} \geq 37$ weeks). Most (90.4\%) were in-hospital born, vaginal delivery accounted for $55.8 \%$ and $44.2 \%$ assisted delivery respectively. About one half (55.8\%) of the patients commenced $\mathrm{MgSO}_{4}$ therapy at $<6$ hours after birth, while $30.6 \%$ and $16.6 \%$ commenced $\mathrm{MgSO}_{4}$ therapy at $6-<24$ hours and $>24$ hours after birth respectively. Time of commencement of first enteral feeding $(\mathrm{p}=0.018)$ and time to full enteral feeding $(\mathrm{p}=0.015)$ showed significant correlation with the survival without neurological deficit. The earlier the commencement of $\mathrm{MgSO}_{4}$ therapy, the better the proportion with strong palmar grasp, sucking reflex, tone and early resolution of encephalo-
\end{abstract}


pathy. Conclusion: All the study subjects treated with magnesium sulphate had impressive improvement; however there is a need to conduct randomized placebo-controlled trial treatment of severe perinatal asphyxia so as to determine its effects on early resolution of hypoxic ischemic encephalopathy/neuroprotective activity.

\section{Keywords}

Severe Perinatal Asphyxia, HIE, Magnesium Sulphate, Neuroprotection, Early Breastfeeding

\section{Introduction}

Perinatal asphyxia is a condition where hypoxaemia and acidosis are present in the foetus or the newborn infants. It is a failure newborn to initiate spontaneous, sustained, and vigorous respiration effort at birth. It is also defined as a failure to initiate spontaneous respirations and/or a 5-minute Apgar score of less than 7: the most commonly used indicator in the identification of birth asphyxia in resource limited settings [1]. Perinatal asphyxia is one of the leading causes of perinatal death and a recognized cause of neuromotor disability among survivors [2]. About $20 \%-30 \%$ of asphyxiated newborns who develop hypoxic ischemic encephalopathy (HIE) die during the neonatal period, and one third to one half of survivors are left with cerebral palsy and mental retardation [3] [4]. Survivors present with several short and long term morbidities, including: seizure disorders, tone abnormalities, feeding difficulties, delayed developmental milestones, learning difficulties, cerebral palsy and mental retardation. The morbidities increase with asphyxia severity. The frequency of severe perinatal asphyxia complications, hypoxic ischemic encephalopathy (HIE) and incidence of up to 26.5/1000 live births is unacceptably high despite advances in perinatal care [5] [6]. Encephalopathy occurs in $50 \%$ to $60 \%$ of patients with severe perinatal asphyxia. Among patients with moderate HIE, $10 \%$ to $20 \%$ die, and $30 \%$ to $40 \%$ develop neurodevelopmental disorders, whereas $50 \%$ of patients with severe HIE die and almost all survivors develop neurodevelopmental deficits [7] [8] [9].

According to Onyearugha et al. [10], findings in some studies in Nigeria reported a prevalence of severe perinatal asphyxia between 46 -63/1000 live births, and this is unacceptably high. The prevalence of severe birth asphyxia in any community is to a large extent dependent on prevailing risk factors, these in turn being influenced by the extent and impact of health education, literacy level, women empowerment, cultural and traditional beliefs affecting efficient utilization of health care services as well as the quality of antenatal, obstetric and neonatal care. Other factors including poverty, ignorance, poor communication network, harmful traditional and cultural practices with significant negative effect on utilization of appropriate health care services by women in pregnancy and labour are particularly rife in the developing countries like Nigeria 


\section{[9] [10].}

Neuro-science research has revealed our understanding of the mechanisms by perinatal asphyxia neuronal damage and adverse consequences. Asphyxia leads to two types of cerebral injuries: the primary neuronal injury that occurs at the time of hypoxic-ischemic insults and the secondary cerebral injury that occurs over hours to days after accumulation of excessive intra-neuronal calcium through stimulation of the excitatory $\mathrm{N}$-methyl-D-aspartate (NMDA) glutamate receptors, which triggers apoptosis of the affected neurons [2].

Magnesium is a naturally occurring NMDA receptor antagonist that blocks neuronal influx of calcium within the ion channels. This block is voltage-dependent and is overcome during axonal depolarization that occurs in hypoxic-ischemic insults. If the extra-cellular magnesium concentration is increased, this blockade can be restored. Finding from earlier studies regarding the effects of magnesium sulphate after stimulated hypoxic-ischemic insults in several animal models revealed neuro-protective effects after administration of intravenous magnesium sulphate at a dose of $250 \mathrm{mg} / \mathrm{kg}$ daily at 24 hours interval within the first three days of delivery preferably of severely asphyxiated newborn [11] [12]. Magnesium sulphate may also have direct actions on mitochondrial activity, anticonvulsant properties and haemodynamic effects by increasing cerebral blood flow. Some data also suggest that $\mathrm{MgSO}_{4}$ may serve an anti-apoptotic role and prevent neuronal cell loss [13] [14] [15]. Magnesium sulphate has wider use in critical care especially by Obstetrician in labour as tocolytic agents and for the suppression of pregnancy induced hypertension and has shown to be beneficial in neonates of treated mothers [7]. However, there is scanty work regarding the role of magnesium sulphate in severely asphyxiated newborn and even the few trials done are not widely circulated thus limiting knowledge and experience on its potential neuroprotective effects. We conducted this interventional trial to assess the potential neuroprotective effect of magnesium sulphate in treating severely asphyxiated newborns and improvement of the neurological outcome.

\section{Justification/Problem Statements}

Perinatal asphyxia especially the severe form is a common problem and contributes significantly to neonatal morbidity and mortality. Encephalopathy occurs in $50 \%$ to $60 \%$ of patients with severe perinatal asphyxia. Patients with moderate HIE $10 \%$ to $20 \%$ die and $30 \%$ to $40 \%$ develop neurodeficits, whereas $50 \%$ of patients with severe HIE die and almost all survivors develop neurodeficits. Magnesium sulphate administration to severely asphyxiated neonate prevent the complication associated with hypoxic-ischemic encephalopathy, so there is need to carry this study so as to encourage its wide application in affected neonates.

\section{Objectives of the Study}

1) General aim: To determine the benefit of magnesium sulphate on perinatal 
asphyxia in neonates presenting UMTH Maiduguri North-Eastern Nigeria.

2) Specific objective:

a) Determine the effect of magnesium sulphate on neurological outcome in severe perinatal Asphyxia.

b) Determine the effect of magnesium sulphate on commencement of oral feed.

c) Determine the effect of magnesium sulphate on reduction of duration of Admission/hospitalization.

\section{Methodology}

\subsection{Study Design}

This was a prospective, interventional study.

\subsection{Study Location}

The Study place is Special Care Baby Unit (SCBU), in the Department of Paediatrics University of Maiduguri Teaching Hospital (UMTH) Maiduguri, the state capital. Borno state is the largest of the six states in the north eastern zone of Nigeria. It lies on latitude $11^{\circ}$ North and longitude $15^{\circ}$ East. It occupies an area of 50,778 square kilometer. Borno state shares borders with republic of Niger to the North, Chad to the North East and Cameroun to the East.

\subsection{Inclusion Criteria}

1) Neonates with severe perinatal asphyxia APGAR score $<3$ at $1 \mathrm{~min}$,

2) Neonates whose mother did not receive anticonvulsants,

3) Neonates whose mother did not receive $\mathrm{MgSO}_{4}$.

\subsection{Exclusion Criteria}

1) Neonates with Apgar's score $>3$ at $1 \mathrm{~min}$,

2) Neonates with congenital malformations,

3) Neonates whose mother had general anaesthesia.

\subsection{Sample Size}

Fifty two (52) was recruited after fulfilling the inclusion criteria.

The sample size was determined using the formula for sample calculation by Glenn with attrition rate estimated at 10\% [16].

\subsection{Ethical Clearance}

Ethical clearance was obtained from the University of Maiduguri Teaching Hospital Research and Ethics Committee.

\subsection{Consent Form}

A form explaining the type of Research, type of sample that was collected and 
treatment given was presented to the parent in detail and to they agreed with the information and granted consent to be included in the study, blood sample was collected from the neonate for the appropriate analysis.

\subsection{Detailed Procedure}

The recruited patients were reviewed, detail history, thorough examination and a diagnosis of severe perinatal asphyxia (with/without) hypoxic ischemic encephalopathy grade I or II (HIE I or II) by one of the researcher or at least senior Paediatrics resident who entered into the proforma. Two separate venous blood sample was taken by the researchers or at least a resident Paediatrician; 1) The first sample of $4 \mathrm{mls}$ was taken in plain bottle for estimation of electrolytes, serum Magnesium, Calcium, lactate dehydrogenase, creatine kinase levels and liver function tests including albumin, aspartate aminotransferases, and alanine aminotransferases. 2) The second blood sample of $1 \mathrm{ml}$ was collected in Ethylene diaminetetracetic acid (EDTA) bottle to estimate the platelets amounts. Immediately after sample collection, the patient received three regimens of intravenous magnesium sulphate infusion at a dose of $250 \mathrm{mg} / \mathrm{kg} / \mathrm{dose}(1 \mathrm{ml} / \mathrm{kg}$ per dose in $20 \mathrm{ml}$ of $5 \%$ dextrose solution) slowly over the period of one hour and blood pressure was checked during this one hour. The remaining two doses repeated at intervals of 24 hours. Patients also received the other standard supportive care and their progress or otherwise was closely monitored. After the last dose of the treatment, serum electrolytes, magnesium, calcium, lactate dehydrogenase, creatine kinase levels and liver function tests including albumin, aspartate aminotransferases, alanine aminotransferases and platelet counts was done.

During these three days of treatment the following vital sings were documented; heart rate, respiratory rate, oxygen saturation with the use of pulse oximeter will be monitored administration of magnesium sulphate. Patient was assessed daily based on neurological status, the grade of hypoxic ischemic encephalopathy (HIE) moderate or severe, the presence of convulsions and the time of establishment of full oral breastfeeding by way of sucking or accepting expressed breast milk with cup and spoon, as well as full neurological examination was done by the same researcher at discharge. This assessment was repeated at follow up at two weeks, six weeks and 3 months after discharge. All these parameters were carefully enter into the proforma with the initial clinical finding documented.

\subsection{Statistical Analysis}

Data generated in this study was entered onto Microsoft Excel and was analyzed using Statistical Package for Social Sciences Version 20 (SPSS software Inc. Chicago, IL, USA). Tables and Charts were used to present frequencies and Prevalence rates. Associations were tested using appropriate statistical tools and $\mathrm{P}$-value of less than $0.05(\mathrm{P} \leq 0.05)$ was considered statistically sig- 
nificant.

\section{Results}

During the period of the study ( $1^{\text {st }}$ August 2017 to $31^{\text {st }}$ July 2018), a total of 52 patients were randomly recruited, comprising of 34 (65.4\%) male and 18 (34.6\%) males, with majority (82.7\%) weighing $\geq 2500 \mathrm{~g}$ at birth. Most (96.2\%) of patient were term baby ( $\mathrm{GA} \geq 37$ weeks). Most (90.4\%) were in-hospital born, vaginal delivery accounted for $55.8 \%$ and $44.2 \%$ assisted delivery respectively. About one half (55.8\%) of the patients commenced $\mathrm{MgSO}_{4}$ therapy at $<6$ hours after birth, while $30.6 \%$ and $16.6 \%$ commenced $\mathrm{MgSO}_{4}$ therapy at $6-<24$ hours and $>24$ hours after birth respectively. Majority (73.1\%) of the mothers were booked and most were booked in either PHC (18.5\%), General hospital (14.8\%) or tertiary hospital (33.3\%). About 58\% were primiparous, while 17 (32.7\%) and 5 (9.6\%) was multipara and grand multipara respectively. The percentage of mothers who did not had prenatal $\mathrm{MgSO}_{4}$ and those who had prenatal $\mathrm{MgSO}_{4}$ was approximately $88.5 \%$ and $11.5 \%$ respectively while $25(48.1 \%)$ of the mothers presented with either preeclampsia or eclampsia. Only $14(26.9 \%)$ of the mothers had antepartum haemorrhage.

Table 1 indicates an unadjusted analysis of factors predicting survival outcome of neonatal asphyxia treated with $\mathrm{MgSO}_{4}$. It largely assessed features like Sex, birth weight, time of first $\mathrm{MgSO}_{4}$ dose, gestation age, place of delivery, mode of delivery, anticonvulsant administration, and antibiotic-use showed no significant association with survival without neurological deficit. However, time to commencement of first enteral feeding $(\mathrm{p}=0.018)$ and time to full enteral feeding $(p=0.015)$ showed significant correlation with the survival without neurological deficit (Table 1). When compared with patients who commenced enteral feeding after 7 days, patient who commenced enteral feeding before 5 days and patient who commenced enteral feeding between $5-7$ days were about 2.6 and 5 folds more likely to survive without neurological deficit.

Table 2 shows crude analysis of maternal factors that could have an influence on neonatal outcome following administration of magnesium Sulphate; however none of the maternal factors demonstrated significant correlation with survival outcomes.

Table 3 presents adjusted analysis of factors with p value, 0.05 in the crude analysis. On adjusted analysis none of the factors showed significant correlation as independent predictors of survival outcome in asphyxia treated with $\mathrm{MgSO}_{4}$.

Table 4 shows the survival outcome of asphyxiated neonate treated with $\mathrm{MgSO}_{4}$ compared across various grades of HIE. There is no significant association between each grade of HIE and survival outcome.

Figure 1 presents percentage with strong suckling reflex distributed after the last dose of $\mathrm{MgSO}_{4}$ dose. The earlier the commencement of $\mathrm{MgSO}_{4}$ therapy the better the percentage with strong suckling reflex at 5 days.

Figure 2 presents percentage with strong Palma grasp distributed by the time 
Table 1. Neonatal factors predicting survival outcome of $\mathrm{MgSO}_{4}$-treated perinatal asphyxia.

\begin{tabular}{|c|c|c|c|c|}
\hline Factors & Total & $\begin{array}{l}\text { F (\%) Alive without } \\
\text { Neurological deficit }\end{array}$ & COR $(95 \mathrm{CI})$ & $p$ value \\
\hline \multicolumn{5}{|l|}{ Sex } \\
\hline Male & 31 & $16(51.6)$ & Reference & \\
\hline Female & 16 & $9(56.2)$ & $1.205(0.358-4.055)$ & 0.763 \\
\hline \multicolumn{5}{|l|}{ Birth weight } \\
\hline $1000-<2500$ & 8 & $5(62.5)$ & $1.583(0.332-7.558)$ & 0.564 \\
\hline$\geq 2500$ & 39 & $20(51.3)$ & Reference & \\
\hline \multicolumn{5}{|c|}{ Time of First $\mathrm{MgSO}_{4}$ dose } \\
\hline$<6$ Hours & 23 & $12(52.2)$ & $1.818(0.350-9.455)$ & 0.477 \\
\hline $6-<24$ Hours & 13 & $9(69.2)$ & $3.750(0.587-23.936)$ & 0.162 \\
\hline$\geq 24$ Hours & 8 & $3(37.5)$ & Reference & \\
\hline \multicolumn{5}{|l|}{ Gestation Age (weeks) } \\
\hline$<37$ & 4 & $2(50.0)$ & Reference & \\
\hline$\geq 37$ & 43 & $23(53.5)$ & $1.150(0.148-8.929)$ & 0.896 \\
\hline \multicolumn{5}{|l|}{ Place of delivery } \\
\hline In-hospital born & 42 & $22(52.4)$ & Reference & \\
\hline Out-hospital born & 5 & $3(60.0)$ & $1.364(0.206-9.016)$ & 0.748 \\
\hline \multicolumn{5}{|l|}{ Mode of delivery } \\
\hline Vaginal delivery & 26 & $12(46.2)$ & Reference & \\
\hline Non-vaginal delivery & 21 & $13(61.9)$ & $1.896(0.588-6.112)$ & 0.284 \\
\hline Time of first enteral feed & & & & 0.018 \\
\hline$<5$ & 16 & $13(81.2)$ & $26.000(2.219-304.702)$ & 0.009 \\
\hline $5-7$ & 24 & $11(45.8)$ & $5.077(0.528-48.855)$ & 0.160 \\
\hline$>7$ & 7 & $1(14.3)$ & Reference & \\
\hline \multicolumn{5}{|c|}{$\begin{array}{l}\text { Time of commencement of } \\
\text { full enteral feeding }\end{array}$} \\
\hline$<7$ & 13 & $11(84.6)$ & $7.857(1.503-41.085)$ & 0.015 \\
\hline$\geq 7$ & 34 & $14(41.2)$ & Reference & \\
\hline \multicolumn{5}{|c|}{ Anticonvulsant administered } \\
\hline Yes & 15 & $6(40.0)$ & Reference & \\
\hline No & 32 & $19(59.4)$ & $2.192(0.628-7.659)$ & 0.219 \\
\hline \multicolumn{5}{|l|}{ Antibiotic administered } \\
\hline Yes & 41 & $23(56.1)$ & $1.917(0.289-12.719)$ & 0.500 \\
\hline No & 5 & $2(40.0)$ & Reference & \\
\hline
\end{tabular}

of first $\mathrm{MgSO}_{4}$ dose. The earlier the commencement of $\mathrm{MgSO}_{4}$ therapy the better the percentage with strong palmar grasp reflex at 5 days. 
Table 2. Maternal factors predicting survival outcome of $\mathrm{h} \mathrm{MgSO}_{4}$-treated neonatal asphyxia.

\begin{tabular}{ccccc}
\hline Factors & Total & $\begin{array}{c}\text { F (\%) Alive without } \\
\text { Neurological deficit }\end{array}$ & COR (95 CI) & p value \\
\hline Booking status & 11 & $5(45.5)$ & Reference & \\
Not booked & 36 & $20(55.6)$ & $1.500(0.386-5.825)$ & 0.558 \\
Booked & & & & \\
Parity & 27 & $14(51.9)$ & $1.615(0.232-11.263)$ & 0.628 \\
Primiparous & 15 & $9(60.0)$ & $2.250(0.285-17.759)$ & 0.442 \\
Multipara & 5 & $2(40.0)$ & Reference & \\
Grandmultipara & & & & \\
Prenatal MgSO & & $3(60.0)$ & $1.364(0.206-9.016)$ & 0.748 \\
Yes & 5 & $22(52.4)$ & Reference & \\
No & 42 & & & \\
Preeclampsia/Eclampsia & & $14(60.9)$ & $1.838(0.576-5.865)$ & 0.304 \\
Yes & 23 & $11(45.8)$ & Reference & \\
No & 24 & $5(45.5)$ & Reference & \\
Yes & 11 & $20(55.6)$ & $1.500(0.386-5.825)$ & 0.558 \\
No & 36 & & &
\end{tabular}

Table 3. Adjusted analysis of factors predicting survival outcome of $\mathrm{h} \mathrm{MgSO}_{4}$-treated neonatal asphyxia.

\begin{tabular}{ccccc}
\hline Factors & Total & $\begin{array}{c}\text { F (\%) Alive without } \\
\text { Neurological deficit }\end{array}$ & AOR (95 CI) & p value \\
\hline $\begin{array}{c}\text { Time of first } \\
\text { enteral feeding }\end{array}$ & & & & \\
$<5$ & 16 & $13(81.2)$ & $12.491(0.722-216.075)$ & 0.083 \\
$5-7$ & 24 & $11(45.8)$ & $4.864(0.504-46.947)$ & 0.171 \\
$>7$ & 7 & $1(14.3)$ & Reference & \\
$\begin{array}{c}\text { Time of commencement } \\
\text { of full enteral feeding }\end{array}$ & & & & \\
$<7$ & 13 & $11(84.6)$ & $2.906(0.302-27.955)$ & 0.356 \\
$\geq 7$ & 34 & $14(41.2)$ & Reference & \\
\hline
\end{tabular}

Figure 3 shows a resolution of encephalopathy and normalization of muscle tone after administration of three doses of magnesium Sulphate.

Figure 4 shows general posture normalization as results of administration of 3 doses of intravenous magnesium Sulphate the severely asphyxiated with hypoxic-ischemic encephalopathy.

We also observed resolution of encephalopathy, normalization of muscle tone and posture. At 3 month in the follow up clinic, greater 50\% were normal without neurodeficits. 
Table 4. Primary outcome of asphyxiated neonates with $\mathrm{HIE}$ treated with $\mathrm{MgSO}_{4}$.

\begin{tabular}{cccc}
\hline HIE & Total & F (\%) Alive & p value \\
\hline Grade 1 & 3 & $3(100.0)$ & 0.561 \\
Yes & 49 & $44(89.8)$ & \\
No & & & \\
Grade 2 & 36 & $15(88.9)$ & 0.583 \\
Yes & 16 & & \\
No & & $13(92.9)$ & 0.714 \\
Grade 3 & 14 & $34(89.5)$ & \\
Yes & 38 & \\
No & &
\end{tabular}

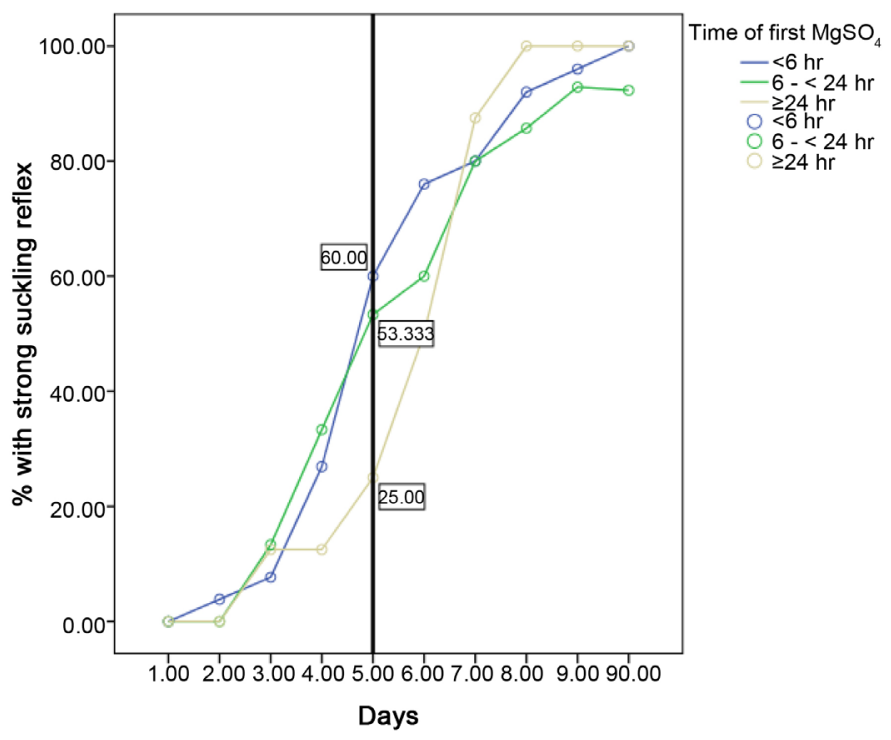

Figure 1. Restoration of sucking reflex after last dose of $\mathrm{MgSO}_{4}$.

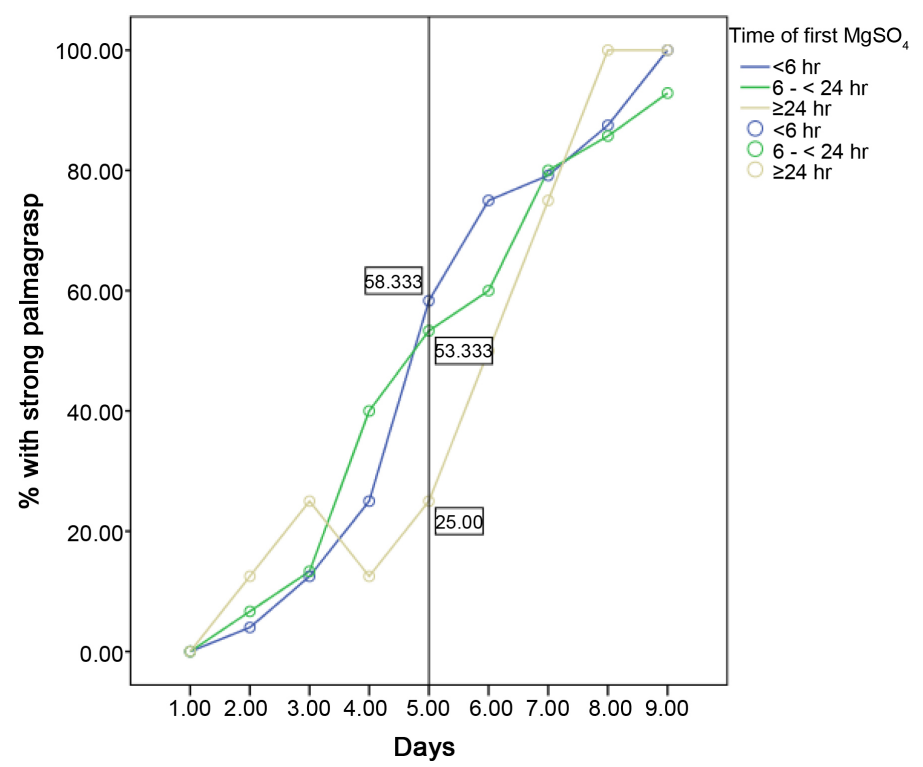

Figure 2. Restoration of palmargrasp after the last dose of $\mathrm{MgSO}_{4}$. 


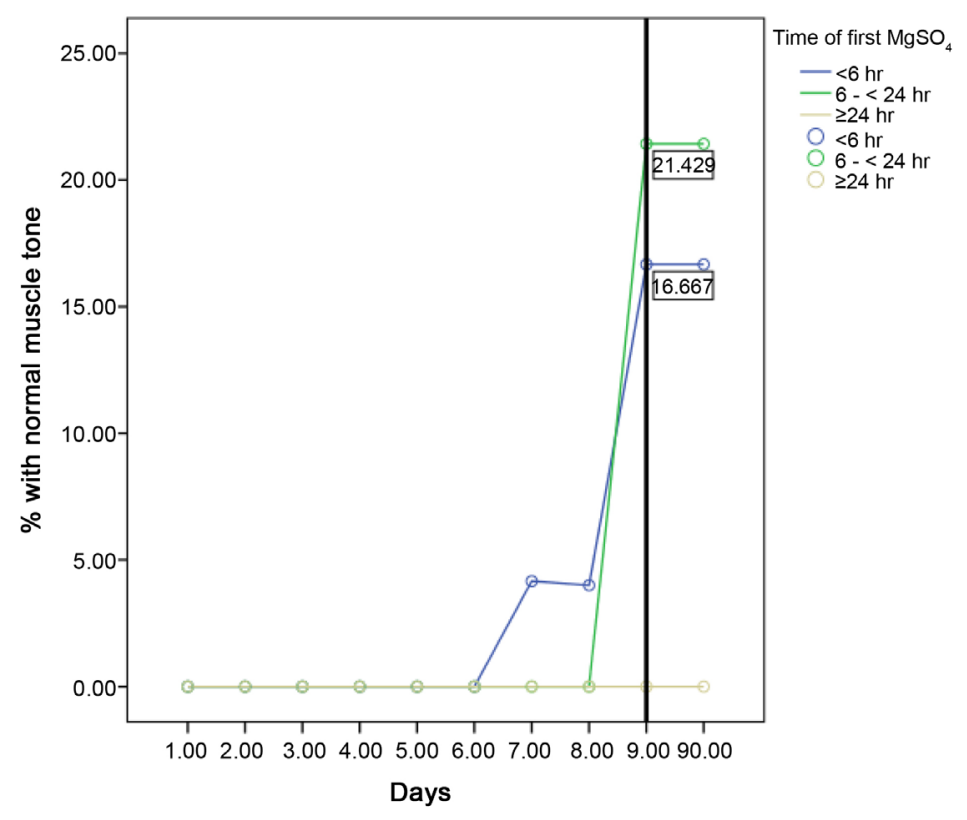

Figure 3. Restoration and normalization of muscle tone as consequence of $\mathrm{MgSO}_{4}$.

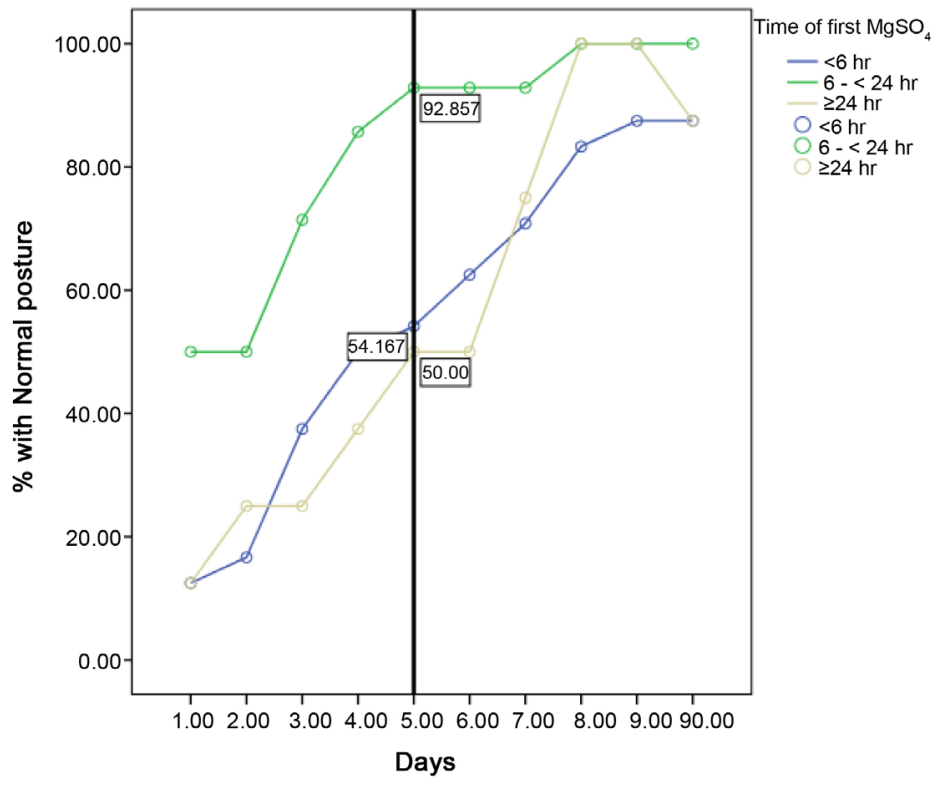

Figure 4. Patients that were treated with $\mathrm{MgSO}_{4}$ and normal tone.

\section{Discussion}

Following severe perinatal asphyxia, hypoxic-ischemic injury of neonatal brain ensues and which said to occur in two phases. The primary phase respond to active resuscitative measures when carried promptly while the secondary phase lingers several hours to days and cause severe irreversible neuronal damages to the developing brain [7]. Glutamate acts on the N-methyle-D-aspartate (NMDA) receptor, a post-synaptic ion channel in the brain, and during asphyxia process, there excessive release and reduced uptake of glutamate in the newborn 
brain [17]. High concentrations of glutamate open channels, allowing excessive calcium influx into the neurons and induce irreversible neuronal. Magnesium Sulphate is a naturally occurring NMDA receptor antagonist that blocks neuronal influx of calcium within the ion channels. It has been found in several researches that when the extracellular concentration of magnesium is increased, then this block is restored thereby halting further brain damages [18].

In this study, we administered to 52 severely asphyxiated neonates that were recruited consecutively after meeting the selection criteria magnesium Sulphate at $250 \mathrm{mg} / \mathrm{kg} / \mathrm{dose}$ daily for the first 72 hours and monitored patients responses to the effects of the drug on the neurological resolution by way of restoration primitive reflexes and regain of consciousness. Approximately half (48\%) of the mothers of asphyxiated babies had intrapartum pre/eclampsia, $26.9 \%$ had antepartum haemorrhages while more than $50 \%$ of the asphyxiated babies were born to obese mother. It was observed that magnesium Sulphate had neuroprotective effects on the study subjects of patients this was evidenced by early restoration of sucking reflexes. In this study majority of the subjects commenced initial feeding with nasogastric tubes (test feed), while full enteral feed by cup and spoon or direct breast feeding were commenced in less than 7 days in most of the patients, these were independent factors that also predicted the survival without neurodeficit as at the time of discharge from the hospital and follow up clinic at 6 weeks. This findings was similar to the reports by Bhat et al., [7] and Ichiba et al. [19].

In this study we evaluated and monitored parameters inaddition early breastfeeding by way of early resumption of sucking reflex includes; normalization of palmar grasp, muscles and resolution of hypoxic ischemic encephalopathy, which was observed in more than $50 \%$ of the patients and was associated survival without neurologic abnormalities as at discharge and at 6 weeks follow in the clinic [20]. Just like in this study, magnesium Sulphate use in human neonates are few and many of the stated neuroprotective role of magnesium Sulphate has been largely done in animal models, with many evidence of favourable results in terms of amelioration of secondary neuronal injury [7] [21]. Unlike study by Bhat and colleagues [7], this index study was randomized non-controlled interventional study, which included all asphyxiated neonates, however, during the study we did not encountered any adverse effects in the neonates; there was no bradycardia, no hypotension and even the few that had apnoea we attributed to severity of the hypoxic-ischemic brain damage before the interventions were instituted. Other workers have also reported similar findings where they found a rapid and good neurological improvement among moderately to severely asphyxiated neonates treated with 3 days daily doses of magnesium Sulphate infusion at $250 \mathrm{mg} / \mathrm{kg}$ [22]. Even though is an interventional trial, it shown a good effect on rapid resolution of hypoxia-ischaemia encephalopathy among magnesium Sulphate treated neonates HIE stage I-III.

\section{Conclusion}

We believe from our interventional trial, magnesium Sulphate has neuroprotec- 
tive effect on severely asphyxiated neonates. If the treatment is administered early after the onset of asphyxia, it surely will halt and probably reverse the secondary neuronal damage due to hypoxic ischemic injury following severe perinatal asphyxia.

\section{Limitation}

This study was non-controlled randomized magnesium Sulphate interventional trial; it will have been better if it were placeb-controlled trial but were unable to do that for ethical reasons. Also we stopped follow up at 3 months, preferably if the patients were followed up to 18 - 24 months post-magnesium study, so that the first two years of the subject growth and development would have more defined with respect to neuromotor deficits as consequences of severe perinatal asphyxia complication. Therefore we suggest further placebo-controlled trial be undertaken to make it robust and more detailed.

\section{Acknowledgements}

The authors are particularly appreciative of the Resident Doctors, Special care Baby Unit (SCBU) of the Department of Paediatrics for their support during the study.

\section{Conflicts of Interest}

The authors have no conflict of interest to declare.

\section{Financial Support and Sponsorship}

The authors received small research grant from TETFUND for IBR. Ref. No. TETFUND/DESS/UNIMAID/MAIDUGURI/RP./VOL.VI. towards the study.

\section{References}

[1] Emechebe, G.O., Ezeogu, J. and Odinaka, K.K. (2016) Birth Asphyxia in Nigeria: A Review. Tropical Journal of Medical and Health Sciences Research, 5, 1-22.

[2] Gathwala, G., Khera, A. and Singh, I. (2006) Magnesium Therapy in Birth Asphyxia. Indian Journal of Pediatrics, 73, 209-212. https://doi.org/10.1007/BF02825482

[3] Barks, J.D.E. and Silverstein, F.S. (1992) Excitatory Amino Acids Contribute to the Pathogenesis of Perinatal Hypoxic Ischemic Brain Injury. Brain Pathology, 2, 235-243. https://doi.org/10.1111/j.1750-3639.1992.tb00697.x

[4] Sreenivasa, B., Lokeshwari, K. and Joseph, N. (2017) Role of Magnesium Sulphate in Management and Prevention of Short Term Complications of Birth Asphyxia. Sri Lanka Journal of Child Health, 46, 148-151. https://doi.org/10.4038/sljch.v46i2.8271

[5] AzraHaider, B. and Bhutta, Z.A. (2006) Birth Asphyxia in Developing Countries: Current Status and Public Health Implications. Current Problems in Pediatric and Adolescent Health Care, 36, 178-188. https://doi.org/10.1016/j.cppeds.2005.11.002

[6] Morales, P., Bustamante, D., Espina-Marchant, P., Neira-Peña, T., GutiérrezHernández, M.A., et al. (2011) Pathophysiology of Perinatal Asphyxia: Can We Predict and Improve Individual Outcomes? EPMA Journal, 2, 211-230. https://doi.org/10.1007/s13167-011-0100-3 
[7] Bhat, M.A., Charoo, B.A., Bhat, J.I., Ali, S.W., Ahmed, M.S. and Mufti, M.U. (2009) Magnesium Sulfate in Severe Perinatal Asphyxia: A Randomized Placebo-Controlled Trial. Pediatrics, 123, 764-769. https://doi.org/10.1542/peds.2007-3642

[8] Dixon, G., Badawi, N. and Kurinczuk, J.J. (2002) Early Developmental Outcome after Newborn Encephalopathy. Pediatrics, 109, 26-33. https://doi.org/10.1542/peds.109.1.26

[9] Robertson, C.M., Finer, N.N. and Grace, M.G. (1989) School Performance of Survivors of Neonatal Encephalopathy Associated with Birth Asphyxia at Term. Jornal de Pediatria, 114, 753-760. https://doi.org/10.1016/S0022-3476(89)80132-5

[10] Onyearugha, C.N. and Ugboma, H.A. (2010) Severe Birth Asphyxia: Risk Factors as Seen in Tertiary Institution of Niger Delta Area of Nigeria. Continental Journal of Tropical Medicine, 4, 11-19.

[11] Crowther, C.A., Hitler, J.E., Doyle, L.W. and Haslam, R.R. (2003) Effect of Magnesium Sulphate Given for Neuroprotection before Preterm Birth. JAMA, 290, 2669-2676. https://doi.org/10.1001/jama.290.20.2669

[12] Penrice, J., Amess, P.N., Punwani, S., Wylezinska, M., Tyszczuk, L., D’Souza, P., et al. (1997) Magnesium Sulfate after Transient Hypoxia-Ischemia Fails to Prevent Delayed Cerebral Energy Failure in the Newborn Piglet. Pediatric Research, 41, 443-447. https://doi.org/10.1203/00006450-199703000-00024

[13] Hossein, M.M., Mannan, M.A., Yeasmin, F., Shaha, C.K., Rahman, M.H. and Shahidullah, M. (2013) Short-Term Outcome of Magnesium Sulphate Infusion in Perinatal Asphyxia Mymensingh Medical Journal, 22, 727-735.

[14] Dune, J.J., Milligan, J.E. and Thomas, B.W. (1971) The Effects of Magnesium Sulphate on Anoxia and Resuscitation in the Neonate. American Journal of Obstetrics and Gynecology, 109, 369-374. https://doi.org/10.1016/0002-9378(71)90330-9

[15] Groenendaal, F., Rademaker, C.M., Toet, M.C. and de Veries, L.S. (2002) Effect of Magnesium Sulphate on Amplitude-Integrated Continuous EEG in Asphyxiated Term Neonates. Acta Paediatrica, 91, 1073-1077. https://doi.org/10.1111/j.1651-2227.2002.tb00102.x

[16] Israel, G.D. (1992) Determining Sample Size. Program Evaluation and Organizational Development, IFAS, University of Florida. PEOD-5 October.

[17] Lorek, A., Takei, Y., Cady, E.B., Wyatt, J.S., Penrice, J., Edwards, A.D., et al. (1994) Delayed ("Secondar") Cerebral Energy Failure after Acute Hypoxic-Ischaemia in the Newborn Piglet: Continuous 48-Hour Studies by Phosphorous Magnetic Resonance Spectroscopy. Pediatric Research, 36, 669-706.

[18] Spandou, E., Soubasi, V., Papoutsopoulou, S., Augustides-Savvoupou, P., Loizidis, T., Pazaitis, A., et al. (2007) Neuroprotective Effect of Long-Term $\mathrm{MgSO}_{4}$ Administration after Cerebral Hypoxia-Ischemia in Newborn Rats Is Related to the Severity of Brain Damage. Reproductive Sciences, 14, 667-677.

https://doi.org/10.1177/1933719107305864

[19] Ichiba, H., Tamai, H., Negishi, H., Ueda, T., Kim, T.J., Sumida, T., et al. (2002) Randomized Control Trial of Magnesium Sulphate Infusion for Severe Birth Asphyxia. Pediatrics International, 44, 505-509. https://doi.org/10.1046/j.1442-200X.2002.01610.x

[20] McDonald, J.W., Silverstein, F.S. and Johnson, M.V. (1990) Magnesium Reduces N-methyl-D-aspartate (NMDA)-Mediated Brain Injury in Perinatal Rats. Neuroscience Letters, 109, 234-238.

[21] Hoffman, D.J., Marro, P.J., McGowan, J.E., Mishra, O.P. and Delivoria-Papadopoulos, 
M. (1994) Protective Effect of Long-Term $\mathrm{MgSO}_{4}$ Infusion on NMDA Receptor Binding Characteristics during Cerebral Cortical Hypoxia in Newborn Piglet. Brain Research, 644, 144-149. https://doi.org/10.1016/0006-8993(94)90357-3

[22] Ichiba, H., Yokoi, T., Tamai, H., Ueda, T., Kim, T.-J. and Yamano, T. (2006) Neurodevelopmental Outcome of Infants with Birth Asphyxia Treated with Magnesium Sulfate. Pediatrics International, 48, 70-75.

https://doi.org/10.1111/j.1442-200X.2006.02167.x 